to continue public education on how to perform hand hygiene, how to mitigate the risk of fomite transmission, and how to use cloth face coverings correctly. The messages are then culturally accepted and espoused by the community so the actions become part of our regular activities. In addition, structural changes within the community and public settings may be required to establish an environment that is favorable to the concepts of minimizing ongoing risk. Finally, similar to enjoying our coffee every morning as part of our daily routine, we will need to experience the satisfaction and reward of performing these safe behaviors as an anchored habit.

\section{Acknowledgments. None.}

Financial support. No financial support was provided relevant to this article.

Conflicts of interest. All authors report no conflicts of interest relevant to this article.

\section{References}

1. Coronavirus disease 2019 (COVID 19): cases, data, and surveillance. Centers for Disease Control and Prevention website. https://www.cdc.gov/ coronavirus/2019-ncov/cases-updates/cases-in-us.html. Accessed May 21, 2020

2. Gould DJ, Moralejo D, Drey N, Chudleigh JH, Taljaard M. Interventions to improve hand hygiene compliance in patient care. Cochrane Database Syst Rev 2017;9:CD005186.
3. Basu A. Estimating the infection fatality rate among symptomatic COVID-19 cases in the United States. Health Aff 2020. doi: 10.1377/ hlthaff.2020.00455.

4. Mehra MR, Desai SS, Kuy S, Henry TD, Patel AN. Cardiovascular disease, drug therapy, and mortality in COVID-19. N Engl J Med 2020. doi: 10.1056/ NEJMoa2007621.

5. Coronavirus (COVID-19) update: FDA informs public about possible accuracy concerns with Abbott ID NOW point-of-care test. US Federal Drug Administration website. https://www.fda.gov/news-events/pressannouncements/coronavirus-covid-19-update-fda-informs-public-aboutpossible-accuracy-concerns-abbott-id-now-point. Accessed May 18, 2020.

6. Brug J, Aro AR, Richardus JH. Risk perceptions and behaviour: towards pandemic control of emerging infectious diseases: international research on risk perception in the control of emerging infectious diseases. Int J Behav Med 2009;16:3-6.

7. Maddux JE, Rogers RW. Protection motivation and self-efficacy: a revised theory of fear appeals and attitude change. J Exp Soc Psychol 1983;19: 469-479.

8. de Zwart O, Veldhuijzen IK, Elam G, et al. Perceived threat, risk perception, and efficacy beliefs related to SARS and other (emerging) infectious diseases: results of an international survey. Int J Behav Med 2009;16:30-40.

9. Brewer NT, Chapman GB, Gibbons FX, Gerrard M, McCaul KD, Weinstein ND. Meta-analysis of the relationship between risk perception and health behavior: the example of vaccination. Health Psychol 2007;26:136-145.

10. Verplanken B, Orbell S. Habit and behavior change. In: Sassenberg K, Vliek MLW, eds. Social Psychology in Action: Evidence-Based Interventions from Theory to Practice. Cham, Switzerland: Springer International; 2019:65-78.

\title{
Lessons learned responding to the COVID-19 pandemic
}

\author{
Anna C. Sick-Samuels MD, MPH ${ }^{1,2}$ (1)
}

${ }^{1}$ Department of Pediatrics, Johns Hopkins School of Medicine, Baltimore, Maryland and ${ }^{2}$ Department of Hospital Epidemiology and Infection Control, Johns Hopkins Hospital, Baltimore, Maryland

To the Editor-The coronavirus disease 2019 (COVID-19) pandemic entered our lives without significant notice. Only a few weeks elapsed from hearing of the first reports of a novel viral pneumonia cluster in Wuhan, China to being faced with a fullblown pandemic affecting our own communities. I had recently joined the faculty as a pediatric infectious diseases physician and associate hospital epidemiologist when COVID-19 rapidly usurped our attention. Within a few days in early March, my attention shifted from defending research grant proposals, contemplating central-line bloodstream infection prevention, and completing clinical notes to assisting the hospital respond to COVID-19 full time. I found myself working with colleagues to rapidly draft new protocols, leading multidisciplinary meetings, and helping the hospital navigate the many new challenges presented by this pandemic. From the perspective of a junior faculty member, I would like to share some of the lessons I have learned from this crash course in emergency response. Though framed by the COVID-19 pandemic, these lessons will remain applicable after COVID-19 has left the main stage.

Author for correspondence: Anna Sick-Samuels, E-mail: asick1@jhmi.edu Cite this article: Sick-Samuels AC. (2021). Lessons learned responding to the COVID19 pandemic. Infection Control \& Hospital Epidemiology, 42: 490-491, https://doi.org/ $10.1017 /$ ice. 2020.293
1. Listen and let people finish. Sometimes it is most important to stop talking and listen. Especially when we are using teleconference or zoom calls and we cannot actually see each other's facial expressions, try to let people finish their sentences. Not only because people have important things to say but also because we feel valued when we are heard. Listening is a way to show respect.

2. Repeat important messages. When the issues and guidance are changing rapidly, we need to repeat the important messages. Repeat to your immediate circle or leadership. Repeat to the broader audience. Repeat with written communications. Repeat with pictures or videos. Repeat in person with individuals.

3. Anxiety is a strong motivator. Especially when working with thoughtful and detail-oriented colleagues. When people do not feel comfortable with a plan, it will not proceed as anticipated and individuals may modify the plan to align with their concerns. Decisions need to consider both physical safety and emotional safety.

4. Brainstorming is different than decision making. As many of us grappled with making decisions for a novel situation with limited data without a precedent to build on, brainstorming discussions occurred on widely attended forums. Sometimes ideas were interpreted as decisions, which can lead to confusion. For those listening, it is important to flag 
brainstorming from decision points. As a listener, it is important to ask for clarity when it is unclear whether a decision was made.

5. Kindness is vital. Recognize where people are coming from, and respond kindly, even if you do not agree. Everyone showing up is present because they care and are willing to chip in. We must be kind to each other and build together.

6. Disagreement is an opportunity. Many times disagreement ultimately leads to better plans. It may take time and patience to revisit decisions and consider different angles. However, these discussions typically lead to a better plan, or an improved communication of the same plan.

7. Be honest about uncertainty. This is a lesson learned during clinical training- that one should not pretend to know the answer when one does not know. Sometimes communicating uncertainty is extremely difficult but it is important to distinguish opinions from facts.

8. Fatigue is real. Physical or emotional. We are all human. It is necessary to self-recognize and protect one's own health, especially when others are counting on you. When we are so tired we cannot think clearly, or so drained we cannot be kind, we are no longer effective leaders, colleagues, parents or partners.

I am tremendously impressed with the response and effort for COVID-19, and I feel fortunate to be facing this crisis surrounded by such thoughtful and dedicated colleagues. The COVID-19 crisis has likely led many of us to reflect on why it is we wake up, leave our family and come to work. So for everyone doing just that, continuing to contribute to keeping our patients and colleagues safe, thank you. Your dedication to patients and the well-being of our communities is amazing. As a result of COVID-19, we will be stronger and more flexible to face the next challenge.

Acknowledgments. The content is solely the responsibility of the authors and does not necessarily represent the official views of the funding agencies.

Financial support. A.C.S. is supported by the National Institutes of Health (grant no. KL2TR003099).

Conflicts of interest. Author reports no conflicts of interest relevant to this article.

\title{
Risk following a severe acute respiratory coronavirus virus 2 (SARS-CoV-2) exposure from a nocturnal hemodialysis patient utilizing continuous positive airway pressure (CPAP)
}

\author{
Christopher F. Lowe MSc, MD, FRCPC ${ }^{1,2}$ (1), Mercedeh Kiaii MD, FRCPC ${ }^{3}$, Laila Aparicio RN, MSCN ${ }^{3}$, \\ Leila Chinybaeva RN, MSc, IMPH ${ }^{1}$, Sandy Coughlin BA ${ }^{4}$, Inna Sekirov PhD, MD, FRCPC ${ }^{5}$, Muhammad G. Morshed PhD ${ }^{5}$ and \\ Victor Leung MD, FRCPC ${ }^{1,2}$ \\ ${ }^{1}$ Infection Prevention and Control, Providence Health Care, Vancouver, Canada, ${ }^{2}$ Department of Pathology and Laboratory Medicine, University of British \\ Columbia, Vancouver, Canada, ${ }^{3}$ Division of Nephrology, Providence Health Care, Vancouver, Canada, ${ }^{4}$ Occupational Health and Safety, Providence Health Care, \\ Vancouver, Canada and ${ }^{5}$ BCCDC Public Health Laboratory, Vancouver, Canada
}

To the Editor-Hemodialysis units are challenging environments to implement infection prevention and control (IPAC) recommendations for coronavirus disease 2019 (COVID-19). ${ }^{1}$ The Centers for Diseases Control and Prevention (CDC) recommends airborne and contact precautions for patients with suspected or confirmed cases of COVID-19. In contrast, the Public Health Agency of Canada has recommended droplet and contact precautions, only recommending airborne precautions for aerosol-generating medical procedures (AGMPs). ${ }^{3}$ Both recommendations are difficult to implement in hemodialysis facilities, which are predominantly open, pod-based units with limited or no single rooms, but recommendations have been developed specifically for dialysis facilities to prevent severe acute respiratory coronavirus virus 2 (SARSCoV-2) transmission. ${ }^{4}$ We describe our experience following an exposure to a nocturnal hemodialysis cohort as a result of an bc.ca

Author for correspondence: Christopher F. Lowe, E-mail: clowe@providencehealth.

Cite this article: Lowe CF, et al. (2021). Risk following a severe acute respiratory coronavirus virus 2 (SARS-CoV-2) exposure from a nocturnal hemodialysis patient utilizing continuous positive airway pressure (CPAP). Infection Control \& Hospital Epidemiology, 42: 491-492, https://doi.org/10.1017/ice.2020.291
AGMP in a patient subsequently confirmed to have coronavirus disease 2019 (COVID-19).

\section{Methods}

The study was conducted at a tertiary-care hospital in Vancouver, Canada. Nocturnal hemodialysis patients are routinely dialyzed in the same pod, which accommodates 12 patients.

Laboratory testing for SARS-CoV-2 was conducted on the cobas 6800 (Roche Molecular Diagnostics, Pleasanton, CA), targeting the Orf-1a and envelope (E) genes. COVID-19 point-of-care serology testing (COVID-19 IgM/IgG antibody test, Artron, Burnaby, Canada) was performed at the provincial reference laboratory.

According to institutional infection prevention and control policies, patients with symptoms consistent with COVID-19 are tested for SARS-CoV-2 with a nasopharyngeal swab. In our hemodialysis unit, patients' temperatures are assessed on arrival and discharge, and any patients with a temperature of $\geq 37^{\circ} \mathrm{C}$ are tested. Suspected or confirmed cases are placed on droplet and contact precautions in a separate pod away from the main cohort. For all hemodialysis patients, staff utilize gowns, gloves, procedure masks, and eye protection during the initiation and conclusion of the 